\title{
DESIGN E SUSTENTABILIDADE: NECESSIDADE DE QUEBRA DE PARADIGMA NO ENSINO
}

\author{
DESIGN AND SUSTAINABILITY: PARADIGM BREACH IN EDUCATION
}

Ana Veronica Pazmino, Dra. (UFSC);
Adriane Shibata Santos, Dra. (UNIVILLE).

Palavras Chave

Sustentabilidade; Design; Ensino

\section{Key Words}

Sustainability, Design; Education

\section{RESUMO}

O artigo defende a necessidade de que nos cursos de design o tema da sustentabilidade seja inserido nos períodos iniciais e permeie o curso nas disciplinas posteriores, sendo tratado como relevante e praticado nas ações projetuais. Assim, pode-se esperar que nos projetos realizados pelos alunos de design sejam considerados problemas sociais e ambientais, além de outras questões relacionadas à sustentabilidade. Apesar do MEC ter estabelecido Diretrizes Curriculares Nacionais para a Educação Ambiental, Relações Étnico Raciais e Direitos Humanos, observa-se, pelos dados resultantes de uma análise curricular da oferta destes conteúdos em disciplinas nos cursos de design de Santa Catarina, que normalmente estes temas não são aplicados de modo transversal, mas como disciplinas. $\mathrm{O}$ artigo finalmente propõe um modelo interdisciplinar da sustentabilidade nos cursos de design, visando que os designers do futuro sejam conscientes e responsáveis da sua atividade.

\section{ABSTRACT}

The article defends the need for the design of courses the topic of sustainability is inserted in the initial periods and permeate the course in subsequent subjects being treated as relevant and practiced in the design actions. Thus, it can be expected that the projects carried out by design students are considered social and environmental issues, and other issues related to sustainability. Although the Ministry of Education has established National Guidelines for Environmental Education, Ethnic Relations Race and Human Rights, the article is a research on the supply of these themes presented in courses in Santa Catarina courses. The article finally proposes an interdisciplinary model of sustainability in design courses aimed that future designers are aware and responsible for their activity. 


\section{INTRODUÇÃO}

O trabalho propõe que os cursos de design insiram a abordagem da sustentabilidade como saber transversal, dentro de uma abordagem interdisciplinar, de modo a ponderar sua contribuição para uma mudança de paradigma no ensino.

A aplicação da abordagem da sustentabilidade no desenvolvimento de produtos faz-se cada vez mais urgente. Para isso é preciso agir com maior sensibilidade e estimular novas relações que saiam das zonas de conforto. É preciso reconstruir a área de estudo e adquirir saberes que ensinem novas formas de conduzir e gerar projetos, atendendo à complexidade da sustentabilidade. Este problema leva a repensar a atividade projetual e a responsabilidade do profissional envolvendo o objeto, o homem, o ambiente e a sociedade. Os objetivos da pesquisa foram: apresentar a relação do ensino de design no Brasil e a sustentabilidade; propor uma ação interdisciplinar de sustentabilidade para o ensino de design. Os procedimentos metodológicos foram de pesquisa documental, e como resultados discutir a inserção do tema da sustentabilidade nos cursos de design visando uma mudança no ensino e na prática projetual dos futuros profissionais.

\section{ENSINO DE DESIGN E O PARADIGMA AMBIENTAL}

As atitudes da população frente ao meio ambiente se apoiam em paradigmas (modelos que servem como parâmetro de referência, considerados, pela maioria, ideais e dignos de serem seguidos, ou seja, é a percepção geral e comum, porém, não necessariamente a melhor).

Até a década de 1960, o paradigma vigente em grande parte da sociedade ocidental fora denominado como Paradigma Social Dominante (PSD). Segundo Silva Filho et. al. (2010), esse paradigma apresentava "uma visão ortodoxa e antropocêntrica na sociedade ocidental", por colocar a relação "ser humano/natureza" de modo que os seres humanos são vistos diferenciados da natureza. Desenvolveu-se principalmente nas nações industriais do norte, num período no qual houve um rápido crescimento material e progresso local, porém sem reflexões sobre os fatores externos a esses países. Por meio deste paradigma, acredita-se num crescimento econômico ilimitado, na abundância de matéria-prima, além da consideração da hegemonia da ciência e tecnologia humana.

A partir deste período, alguns autores destacam uma alteração da abordagem em relação ao meio ambiente por grande parte das sociedades modernas. Da denúncia de Rachel Carson sobre o uso de pesticidas, apresentado no livro Primavera Silenciosa, abriu-se caminho para uma nova forma de pensar, colocando o ser humano como parte do sistema. Outra publicação importante foi, em 1972, o relatório Limites do Crescimento, que modelava matematicamente doze futuros possíveis e as consequências do crescimento constante da população e da economia no contexto de recursos limitados do planeta, incluindo a capacidade limitada da terra de "absorver a poluição".

O modelo reconhecia que a atividade humana interage com o mundo natural e o afeta, sendo capaz de "induzir o seu colapso". Desde então aconteceram impactos ambientais e alguns de impacto global. A ciência apresenta graves problemas do meio ambiente, mostrando que estamos diante de um risco significativo de enorme mudança, que ameaça a prosperidade e estabilidade da sociedade humana.

Dunlap, Catton, Pirages e Van Lie reconsideram como uma consequência dessa reflexão a criação de um novo paradigma sócio ambiental, dando destaque ao papel do meio ambiente na nova interpretação econômica (SILVA FILHO et. al., 2010). Esse novo paradigma foi inicialmente denominado de Novo Paradigma Ambiental (NPA) e posteriormente de Novo Paradigma Ecológico (NPE). Considera que embora os homens tenham características excepcionais, tais como a tecnologia e a cultura, são dependentes das outras espécies do ecossistema. Este paradigma está sendo considerado ideal e digno de ser seguido de forma lenta ao longo das últimas 60 décadas.

Porém, a ação dos indivíduos pouco tem-se modificado acompanhado o Novo Paradigma Ecológico. Segundo Gilding (2014), o meio ambiente está sendo usado de modo insustentável e se os comportamentos não mudarem, ele deixará de estar disponível para uso. Segundo o autor, em 2009, a população global precisava de 140\% da terra disponível, ou seja, 1,4 do planeta. Sendo que em 1986 foi ultrapassada a capacidade da Terra, e desde então os seres humanos estão excedendo essa capacidade. Isso significa que a sociedade com suas ações está exaurindo o capital todos os dias apenas para sobreviver.

Kolbert $(2015$, p. 199) destaca a relação direta do homem com o ecossistema e a relação de dependência entre ambos: [...] permanecemos dependentes dos sistemas biológicos e geoquímicos da Terra. Ao perturbarmos esses sistemas - derrubando florestas tropicais, alterando a composição da atmosfera, acidificando os oceanos -, estamos colocando em risco nossa própria sobrevivência. [...] O antropólogo Richard Leakey já advertiu que o "Homo Sapiens" pode ser não apenas o agente da sexta extinção, mas corre o risco de ser uma de suas 
vitimas'. Um cartaz no Salão da Biodiversidade cita uma frase do ecologista de Standford Paul Ehrlich: ao pressionar outras espécies para a extinção, a humanidade está serrando o galho sobre o qual está sentada. (KOLBERT, 2015, p. 199)

Com tantos fatos relatados desde a década de 1960, observa-se que no campo do design a preocupação ambiental também surgiu mais ou menos neste período, destacando-se Victor Papanek, que em 1971 publicou o livro "Design for the real Word", no qual ele criticava o posicionamento e ações do designer e mencionava que havia profissões mais prejudiciais que o desenho industrial, mas bem poucas. Em 2009, Nathan Shedroff publicou o livro "Design is the problem: the future of design must be sustainable", no qual apontava que o design tem criado grandes problemas no mundo. Segundo Shedroff (2009), os designers são ensinados a fazer novos produtos quando na verdade um produto deveria ter um longo ciclo de vida ou permitir ser consertado.

Por outro lado, John Thackara publicou em 2005 o livro "In the Bubble: Designing in a Complex World", no qual ele aborda o design e suas alternativas para um mundo complexo, defendendo que ainda há muitas coisas erradas com o design atual, mas que também há soluções de produtos, serviços e sistemas sendo desenvolvidos que são radicalmente menos prejudiciais ao ambiente $\mathrm{e}$ mais socialmente responsáveis. No entanto, ele enfatiza e prioriza a necessidade de algumas mudanças: "Nessa nova era de inovação colaborativa, os designers estão tendo de evoluir de autores individuais de objetos, a facilitadores da mudança entre grandes grupos de pessoas" (THACKARA, 2008, p. 21).

No ensino de design observa-se o que (MARGOLIN e MARGOLIN, 2004) mencionam, de que o paradigma do design dominante tem sido o de projetar para o mercado, dessa forma, o "modelo para o mercado" já está muito bem desenvolvido. Já para o design social e design sustentável pouca teoria e métodos têm sido desenvolvidos.

De modo geral, o ensino de design tem permanecido fechado em si mesmo, isolado dos problemas ambientais. São enfatizadas teorias e abordagens de inovação, mercado e consumo, mas questões relacionadas ao meio ambiente e sustentabilidade são pouco inseridas nas instituições de ensino.

Desde 1963, na criação da Escola Superior de Desenho Industrial, o currículo foi composto por disciplinas relacionadas ao mercado e à indústria, mesmo que nos Estados Unidos e na Europa já se mencionavam os problemas ambientais, estes não foram inseridos nos currículos brasileiros.
Segundo COUTO (2008) na aérea do design, o esforço heroico no sentido de atualizar currículos, introduzir novas disciplinas e promover discussões sobre questões da atualidade vem sendo empreendido ao longo dos anos por muitos docentes e pesquisadores.

As diretrizes curriculares nacionais para bacharelados em design, por meio do parecer CES/CNE 0195/2003 aprovado em 05/08/2003 e publicado no Diário Oficial em 12 de fevereiro de 2004, e da Resolução CNE/CES5/2004 de 8 de março de 2004, que dita as diretrizes específicas para cursos de bacharelado em Design, apresentam descaso à questão ambiental e mostram que são grandes os desafios para que este tema seja inserido nos cursos de design. Dos treze artigos do parecer apenas o Art. $5^{\circ}$ inciso I é mencionado o tema ambiental:

Art. $5^{\circ} \mathrm{O}$ curso de graduação em Design deverá contemplar, em seus projetos pedagógicos e em sua organização curricular conteúdos e atividades que atendam aos seguintes eixos interligados de formação: I - conteúdos básicos: estudo da história e teorias do design em seus contextos sociológicos, antropológicos, psicológicos e artísticos, abrangendo métodos e técnicas de projetos, meios de representação, comunicação é informação, estudo das relações usuário/objeto/meio ambiente, estudo de materiais, processos, gestão e outras relações com a produção e o mercado. (COUTO, 2008 p. 73)

Percebe-se que a trajetória do design no Brasil não ficou atenta ao novo paradigma ambiental e que houve descaso tanto na definição das diretrizes curriculares, como na elaboração dos currículos dos cursos de design, em que disciplinas relacionadas ao meio ambiente e sustentabilidade não são consideradas relevantes.

Em 2012 foi publicada a Resolução CNE/CP2/2012, que estabelece as Diretrizes Curriculares Nacionais para a Educação Ambiental, "a serem observadas pelos sistemas de ensino e suas instituições de Educação Básica e de Educação Superior, orientando a implementação do determinado pela Constituição Federal e pela Lei n. 9.795, de 1999, a qual dispõe sobre a Educação Ambiental (EA) e institui a Política Nacional de Educação Ambiental (PNEA)". Destaca-se no Artigo $15^{\circ}$ a Organização Curricular e no Artigo $16^{\circ}$ a inserção dos conteúdos nos currículos:

Art. 15. O compromisso da instituição educacional, o papel socioeducativo, ambiental, artístico, cultural e as questões de gênero, etnia, raça e diversidade que compõem as ações educativas, a 
organização e a gestão curricular são componentes integrantes dos projetos institucionais e pedagógicos da Educação Básica e da Educação Superior.

$\S 1^{\circ}$ A proposta curricular é constitutiva [...] dos Projetos Pedagógicos de Curso (PPC) e do Projeto Pedagógico (PP) constante do Plano de Desenvolvimento Institucional (PDI) das instituições de Educação Superior.

$\S 2^{\circ}$ O planejamento dos currículos deve considerar os níveis dos cursos, as idades e especificidades das fases, etapas, modalidades e da diversidade sociocultural dos estudantes, bem como de suas comunidades de vida, dos biomas e dos territórios em que se situam as instituições educacionais.

$\S 3^{\circ} \mathrm{O}$ tratamento pedagógico do currículo deve ser diversificado, permitindo reconhecer e valorizar a pluralidade e as diferenças individuais, sociais, étnicas e culturais dos estudantes, promovendo valores de cooperação, de relações solidárias e de respeito ao meio ambiente.

Art. 16. A inserção dos conhecimentos concernentes à Educação Ambiental nos currículos da Educação Básica e da Educação Superior pode ocorrer:

I - pela transversalidade, mediante temas relacionados com o meio ambiente e a sustentabilidade sócio ambiental;

II - como conteúdo dos componentes já constantes do currículo;

III - pela combinação de transversalidade e de tratamento nos componentes curriculares.

Parágrafo único. Outras formas de inserção podem ser admitidas na organização curricular da Educação Superior e na Educação Profissional Técnica de Nível Médio, considerando a natureza dos cursos. (Resolução CNE/CP2/2012)

Nos currículos dos cursos de design os temas relacionados ao meio ambiente e sustentabilidade normalmente aparecem como uma disciplina e não como temas transversais. Este modelo representa as propostas de organização do currículo baseadas na adoção de "disciplinas", cada qual com um conjunto de conteúdos organizados e delimitados. Neste caso, a sustentabilidade como tal, tem um conteúdo programático estabelecido e adequado para cada ano, semestre ou período letivo em que é ofertado no ensino superior, tem objetivos educacionais previamente estabelecidos nos planos de ensino e a adoção de um sistema de avaliação bem definido. Este modelo representa a inclusão da sustentabilidade no chamado sistema tradicional de ensino.

Em um levantamento preliminar em sites de cursos de design no Estado de Santa Catarina, observa-se que as disciplinas relacionadas ao meio ambiente e sustentabilidade são oferecidas em fases avançadas, algumas são normalmente oferecidas em fases avançadas, em algumas IES são disciplinas complementares e em outras não existem disciplinas relacionadas, como pode ser visto no quadro 1.

Quadro 1 - Disciplinas de design e sustentabilidade em IES de SC

\begin{tabular}{|c|c|c|c|}
\hline Instituição & Período & Disciplina & $\begin{array}{c}\text { Carga } \\
\text { Horária }\end{array}$ \\
\hline $\begin{array}{l}\text { Católica } \\
\text { Jaraguá do } \\
\text { Sul }\end{array}$ & $\begin{array}{c}7^{\circ} \\
\text { Semestre }\end{array}$ & Ambientalismo & 60 \\
\hline $\begin{array}{l}\text { Católica } \\
\text { Jaraguá do } \\
\text { Sul }\end{array}$ & $\begin{array}{c}7^{\circ} \\
\text { Semestre }\end{array}$ & $\begin{array}{l}\text { Pesquisa de } \\
\text { novos materiais } \\
\text { sustentáveis }\end{array}$ & 60 \\
\hline $\begin{array}{c}\text { Faculdade } \\
\text { Energia } \\
\text { FEAN }\end{array}$ & $5^{\mathrm{a}}$ Fase & $\begin{array}{c}\text { Sustentabilidade } \\
\text { e Gestão } \\
\text { Ambiental }\end{array}$ & 36 \\
\hline $\begin{array}{c}\text { IFSC } \\
\text { Florianópolis }\end{array}$ & $\begin{array}{c}\text { Não } \\
\text { encontrado }\end{array}$ & Não encontrado & $\begin{array}{l}\text { Não en- } \\
\text { contrado }\end{array}$ \\
\hline UDESC & $\begin{array}{c}\text { Não } \\
\text { encontrado }\end{array}$ & Não encontrado & $\begin{array}{l}\text { Não en- } \\
\text { contrado }\end{array}$ \\
\hline UFSC & $\begin{array}{l}\text { Obrigatória } \\
\text { e pode ser } \\
\text { feita em } \\
\text { qualquer } \\
\text { período }\end{array}$ & $\begin{array}{c}\text { Design e } \\
\text { Sustentabilidade }\end{array}$ & 54 \\
\hline UNISUL & $\begin{array}{c}5^{\circ} \\
\text { Semestre }\end{array}$ & $\begin{array}{l}\text { Introdução ao } \\
\text { Eco-Design }\end{array}$ & $\begin{array}{l}30 \text { Com- } \\
\text { plementar }\end{array}$ \\
\hline UNISUL & $\begin{array}{c}5^{\circ} \\
\text { Semestre }\end{array}$ & $\begin{array}{c}\text { Materiais } \\
\text { e Insumos } \\
\text { Adequados à } \\
\text { Preservação do } \\
\text { Meio Ambiente }\end{array}$ & $\begin{array}{l}30 \text { Com- } \\
\text { plementar }\end{array}$ \\
\hline UNISUL & $\begin{array}{c}6^{\circ} \\
\text { Semestre }\end{array}$ & $\begin{array}{l}\text { Projeto de } \\
\text { Viabilidade em } \\
\text { Eco-Design }\end{array}$ & $\begin{array}{l}60 \text { Com- } \\
\text { plementar }\end{array}$ \\
\hline UNISUL & $\begin{array}{c}7^{\circ} \\
\text { Semestre }\end{array}$ & $\begin{array}{c}\text { Projeto } \\
\text { Conceitual e } \\
\text { Experimental em } \\
\text { Eco-Design }\end{array}$ & $\begin{array}{l}60 \text { Com- } \\
\text { plementar }\end{array}$ \\
\hline
\end{tabular}




\begin{tabular}{|c|c|c|c|}
\hline UNIVALI & $\begin{array}{c}7^{\circ} \\
\text { Semestre }\end{array}$ & $\begin{array}{c}\text { Design e Meio } \\
\text { Ambiente }\end{array}$ & $\begin{array}{c}\text { Não men- } \\
\text { cionado }\end{array}$ \\
\hline UNIVILLE & $4^{\circ}$ Ano & $\begin{array}{c}\text { Design, ética } \\
\text { e sustentabili- } \\
\text { dade (NC) }\end{array}$ & 72 \\
\hline
\end{tabular}

Fonte: Elaborado pelo autor, com base na pesquisa realizada.

Mesmo que a sustentabilidade não apareça como conteúdo exigido nas diretrizes curriculares de bacharelado em design, observa-se que são oferecidas disciplinas relacionadas a este tema na maioria das IES analisadas. Isso por iniciativa de docentes e pesquisadores, mas acredita-se também, que devido às Diretrizes Curriculares Nacionais para a Educação Ambiental, Relações Étnicoraciais e Direitos Humanos.

O problema é que temas relacionados à sustentabilidade tratados como disciplinas, sem relação com outras disciplinas do curso, fazem com que a sustentabilidade não seja aplicada de modo mais abrangente nos projetos de design. Por outro lado, quando as disciplinas são cursadas no final do curso, não têm seus conteúdos assimilados de forma significativa, apesar de uma maior maturidade por parte dos acadêmicos. Deve-se lembrar que nos cursos de design a ação projetual é realizada ao longo do curso e que no processo de design são construídos modelos e protótipos, de modo que toda materialização também provoca impactos. Com isso, um aluno que não teve contato com a temática da sustentabilidade muito provavelmente não irá refletir sobre suas ações projetuais e sobre as decisões tomadas ao longo do projeto, que podem provocar impactos ao longo do ciclo de vida de um modelo, protótipo e, no mercado de trabalho, no produto final.

Para o tema da sustentabilidade, seria adequado pensar de forma interdisciplinar, em que os conceitos da disciplina percorram o curso de forma transversal e os conteúdos se integrassem numa visão mais holística.

Fontoura (2002) menciona que, ainda que utópica, esta parece ser a condição ideal para se promover uma educação significativa, na qual o conhecimento é tratado como um todo. Porém, a prática desta proposta é quase impossível, uma vez que ela exige um preparo e uma formação que hoje ainda pouquíssimos professores têm e de uma flexibilidade administrativa e organizacional que poucos sistemas de ensino possuem e permitem.

\section{A INSERÇÃO DO DESIGN PARA A SUSTENTABILIDADE}

Mais do que nunca, observa-se atualmente a necessidade de que os designers compreendam a responsabilidade que suas ações e decisões projetuais têm sobre as soluções dos produtos e ao longo do processo produtivo e que o desenvolvimento de produtos deve ser baseada numa compreensão do impacto ambiental de cada aspecto da produção, uso, descarte, reciclagem (do berço ao berço).

Deste modo, é necessária a discussão sobre qual o meIhor modo de inserir a educação ambiental no campo do design. A aplicação de uma abordagem de design para a sustentabilidade deve considerar uma série de questões: Como deve ser inserido o tema da sustentabilidade no currículo dos cursos de design? Que papel um docente pode desempenhar para incentivar a reflexão dos alunos sobre o tema da sustentabilidade? Que papel um designer pode desempenhar num processo de projeto com foco ambiental? O que está sendo feito e o que pode ser feito? Como a percepção pública da atividade de design pode mudar no sentido de apresentar uma imagem de um designer ambientalmente e socialmente responsável? Que tipos de produtos diminuem os impactos ambientais? Que tipos de materiais são adequados para o desenvolvimento de produtos?

A resposta para estes questionamentos pode vir de temas tratados nos cursos de design. É preciso que o designer assuma as responsabilidades das ações projetuais e principalmente que intencionalmente projete de forma amigável ao meio ambiente e para a sociedade e não apenas para o mercado.

\subsection{Sustentabilidade como tema transversal}

Fontoura (2002) menciona que os temas transversais têm como proposta básica promover e priorizar a integração das questões sociais e estão orientados à formação da cidadania e à afirmação democrática, sendo eles: Ética, Meio Ambiente, Pluralidade Cultural, entre outros.

Nesta concepção, os conteúdos curriculares tradicionais ainda formam o eixo longitudinal do sistema educacional e, em torno dessas áreas de conhecimento, circulam ou perpassam transversalmente, temas mais vinculados ao cotidiano da sociedade.

Segundo Urbam, Maia e Scheibel (2009) com o tema meio ambiente, o aluno deverá perceber relações que condicionam a vida para posicionar-se de forma crítica diante do mundo, além de dominar métodos de manejo e conservação ambiental.

Na proposta desta pesquisa, conforme modelo da Figura 1 , a sustentabilidade aparece como um tema transversal, que integra os conteúdos de diversas disciplinas ou áreas de conhecimento. A adoção de áreas de conhecimento e dos temas transversais é recomendada por diversos sistemas educacionais - inclusive pelas novas diretrizes educacionais brasileiras. 
Figura 1: Modelo transversal

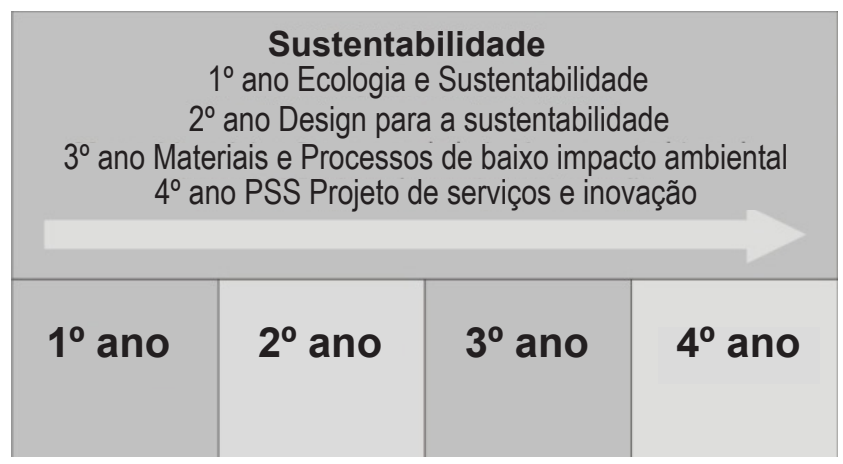

Fonte: Elaborado pelo autor, com base na pesquisa realizada.

Nos cursos de design, sugere-se que o tema transversal da sustentabilidade integre conteúdos das disciplinas do curso, permitindo que o aluno desenvolva uma visão ampla de relação entre meio ambiente, usuário e produto e uma visão holística sobre problemas atuais que atingem a sociedade, sensibilizando-o para as questões mais relevantes com relação à responsabilidade ético sócio ambiental no desenvolvimento de suas atividades profissionais. Permitirá, também, formar seu código de conduta para ser um cidadão crítico, atuante e reflexivo nos temas relacionados às diferentes dimensões da sustentabilidade.

Para isso, faz-se necessário que disciplinas que abordem a educação ambiental e a sustentabilidade sejam consideradas básicas e obrigatórias, perpassando pelas diversas dimensões da sustentabilidade (econômica, social, ambiental, ecológica, territorial, cultural e política).

No primeiro ano disciplina de trate do contexto da ecologia e sustentabilidade como problemática social, no segundo ano quando o aluno começa a ter contato com disciplinas relacionadas a atividade projetual o tema pode estar relacionado a aplicação prática da sustentabilidade no projeto de baixa complexidade, no terceiro ano o aluno teria contato com materiais e processos de baixo impacto ambiental e no quarto ano os temas seriam relacionados a novas tendências da aplicação da sustentabilidade.

A partir destas discussões, o aluno de design estará apto a identificar métodos, técnicas e ferramentas para que possam criar produtos e serviços de baixo impacto ambiental, que considerem as necessidades humanas, e de forma responsável para com o meio ambiente e a sociedade.

\section{CONCLUSÃO}

No aspecto educacional, observa-se que a sustentabilidade ainda não faz parte das matrizes curriculares da maioria dos cursos de design de Santa Catarina, mesmo após a definição das Diretrizes Curriculares Nacionais para a Educação Ambiental. Quando o tema é inserido, acaba sendo abordado em uma disciplina isolada, que geralmente não mantém uma relação interdisciplinar com as outras disciplinas do curso.

Considerando as ações do designer, cabe salientar que os três fatores essenciais que determinam o impacto ambiental humano - população, riqueza e tecnologia (inclusive o comportamento em relação a ela) - são também alavancas que podem ser acionadas para diminuir o impacto.

A tecnologia está cada vez mais inserida na atividade projetual, de modo que, atualmente, com a fabricação digital, maquetes ou modelos são confeccionadas rapidamente e após a apresentação do projeto são descartados sem um cuidado em relação ao acúmulo de lixo.

Reflexões sobre a relação entre a ação projetual e a materialização, como também de problemáticas da sustentabilidade, devem estar presentes no ensino de design desde as fases inicias e permear o currículo dos cursos, como acontece com disciplinas que fazem parte a mais tempo do campo do design. A aplicação desta abordagem como tema transversal poderá, no longo prazo, formar designers mais comprometidos com a problemática ambiental e social.

\section{REFERÊNCIAS}

COUTO, R. M. de S. Escritos sobre ensino de design no Brasil. Rio de Janeiro: Rio Books, 2004.

DEFORGE, Y. Por um Design Ideológico. In: Estudos em Design, volume II, número 1, Rio de Janeiro, 1994.

FONTOURA, A. M. Edade: a educação de crianças e adolescentes através do design. Tese de Doutorado em Engenharia de Produção. Universidade Federal de Santa Catarina, Florianópolis, 2002.

GILDING, Paul. A grande ruptura: Como a crise climática vai acabar com o consumo e criar um novo mundo. Rio de Janeiro: Apicuri, 2014.

KOLBERT, Elizabeth. A sexta extinção: Uma história não natural. Rio de Janeiro: Intrínseca, 2015.

MAIA, Christiane; SCHEIBEL, Maria; URBAN, Ana Claudia. Didática: Organização do trabalho pedagógico. Curitiba: IESDE Brasil S.A, 2009.

PAPANEK, V. Design para el mundo real: Ecología humana e cambio social. Madrid: Ediciones Blume, 1977.

SILVA FILHO, José Carlos Lázaro et.al. Estudo sobre 
o Novo Paradigma Ecológico (NPE) no Brasil: medindo a consciência ambiental através da Escala-NEP. In: Anais do XXXIV Encontro da ANPAD. Rio de Janeiro, 2010. Disponível em: <http://www.anpad.org.br/admin/pdf/ gct1133.pdf>. Acesso em: 26 abr. 2016.

MARGOLIN, Sylvia, MARGOLIN, Victor. Um Modelo Social de Design: questões de prática e pesquisa. Revista Design em Foco 2004, I (julho-dezembro): [Fecha de consulta: 25 de abril de 2016] Disponível em: <http://www. redalyc.org/articulo.oa?id=66110105> ISSN 1807-3778

SHEDROFF, Nathan. Designis the problem: The future of design must be sustainable. New York: Rosenfeld Media, 2009.

THACKARA, J. Plano B: o design e as alternativas viáveis em um mundo complexo. São Paulo: Saraiva: 